\title{
The occurrence of childhood diarhea and its home management among mothers of under-five years children in Arba Minch Zuria, Southern Ethiopia
}

\author{
Shikur Mohammed ${ }^{1}$, Dessalegn Tamiru ${ }^{2}$ \\ ${ }^{1}$ Department of Public Health, Arba Minch University, Ethiopia \\ ${ }^{2}$ Department of reproductive health and nutrition, Jimma University, Ethiopia \\ Email address: \\ shikurmohamed@yahoo.com(S. Mohammed); dassutami@yahoo.com(D. Tamiru)
}

\section{To cite this article:}

Shikur Mohammed, Dessalegn Tamiru. The Occurrence of Childhood Diarhea and Its Home Management among Mothers of Under-Five Years Children in Arba Minch Zuria, Southern Ethiopia. Science Journal of Public Health. Vol. 1, No. 3, 2013, pp. 135-140. doi: 10.11648/j.sjph.20130103.15

\begin{abstract}
Introduction: In Ethiopia the prevalence of diarrhea morbidity is more common in rural than in urban areas. To address this problem, interventions have been going on based on the guidelines. There is no study that assessed whether the management of childhood diarrhea is according to the guideline or not. Therefore, the aim of this study was to assess the occurrence of childhood diarrhea and its home management among mother of under-five year children in Arba Minch Zuria. Methods: A community based cross-sectional study was conducted in February 2012. A multistage sampling technique was used to select 590 households that had at least one under-five child. Data were collected using pre-tested structured questionnaire by trained data collectors. The data were entered and analyzed using SPSS (SPSS Inc. version 16.0, Chicago, Illinois). Descriptive statistics (frequencies, proportion and chi- square test) were used to describe the study population in relation to relevant variables. Results: In this study prevalence of diarrhea was found $30.5 \%$. which was significantly associated with mother education level $\left(\mathrm{X}^{2}=6.0397, \mathrm{df}=1, \mathrm{p}\right.$-value $\left.=0.0139\right)$, knowledge about diarrhea $\left(\mathrm{X}^{2}=5.0234, \mathrm{df}=1\right.$, $\mathrm{p}$-value $=0.0250)$, floor types of the house $\left(\mathrm{X}^{2}=5.1428, \mathrm{df}=1, \mathrm{p}\right.$-value $\left.=0.0233\right)$. number of rooms $\left(\mathrm{X}^{2}=30.46, \mathrm{df}=2, \mathrm{p}\right.$ value $<0.00001)$, latrine type $\left(\left(\mathrm{X}^{2}=25.5929, \mathrm{df}=1, \mathrm{p}\right.\right.$-value $\left.<0.00001\right)$, type of water transportation container $\left(\mathrm{X}^{2}=\right.$ $47.878, \mathrm{df}=1, \mathrm{p}$-value $=0.00001)$, and mother hand washing practice $\left(\mathrm{X}^{2}=15.4182, \mathrm{df}=1, \mathrm{p}\right.$-value $\left.=0.0001\right)$. The study also showed $31 \%$ of mothers didn't give anything to control or manage the diarrhea. Conclusion: The finding showed that the occurrence of diarrhea is high in the study area. As significant number of the mothers do not have adequate knowledge on the occurrence and management of diarrhea. Counseling mothers on the three rules of home treatment; give extra fluid, continue feeding and advise the mother when to return health facility is very crucial for the control and the prevention of the disease. Reducing diarrhea morbidity also involves providing better sanitation for the entire population and hygiene of the person caring of the child.
\end{abstract}

Keywords: Under Five Year Children, Acute Diarrhea, Management of Childhood Diarrhea

\section{Introduction}

Diarrheal diseases are leading cause of preventable death, especially among children under five in developing countries [1]. Acute diarrheal diseases are one of the main problems affecting children in the world, reducing their well-being and creating considerable demand for health services [2]. Diarrheal disease affects human life both in developed and developing countries. Nevertheless a strong relationship exists between poverty and unhygienic environment. Poverty restricts the mothers to provide ageappropriate, nutritionally balanced diets or to modify diets when diarrhea develops so as to alleviate and repair nutrient losses. The frequency and severity of diarrhea is aggravated by lack of access to sufficient clean water and sanitary disposal of human waste; inadequate feeding practices and hand washing; poor housing conditions and lack of access to adequate and affordable health care $[3,4]$.

Inappropriate child feeding practices has also a major public health problem resulting in series social and economic consequences especially in developing countries 
[5]. The failure to exclusively breastfeed young infants to 6 months and the introduction of liquids and solid foods at too early age increases the risk of diarrheal disease and an important cause of morbidity and mortality in Africa [6].

To reduce the morbidity and mortality associated with infectious diarrhea, the clinical and public health practitioner communities must work closely together to identify optimal diagnostic, treatment, and prevention methods. A better understanding of the interaction between persistent diarrhea and malnutrition as causes of mortality has drawn increased attention to the need to expand the scope of intervention programs, whose therapeutic basis is oral rehydration therapy. The primary goal of treating diarrheal diseases is preventing dehydration or appropriately rehydrating persons with dehydration [7].

Oral rehydration solutions (ORS) or commercially available solutions made of appropriate amounts of sodium, potassium and glucose should be used for rehydration if patients can consume or drink the required volumes; otherwise appropriate intravenous fluids may be used [7-9]. Some studies and scholars recommended two general methods for an effective treatment of diarrheal disease, ORS and zinc supplementations [8]. Therefore, determining the magnitude of childhood diarhea and knowing how mothers/caretakers manage childhood diarhea is very important for the better decision and health planning.

\section{Methods and materials}

\subsection{Study Setting and Sample}

Community based cross-sectional study was conducted in Arba Minch Zuria District, Southern Ethiopia, located at $505 \mathrm{~km}$ from Addis Ababa. The sample size was calculated using single population proportion formula using the following parameters: 95\% confidence level (1.96), Margin of error (0.05), $25.5 \%$ proportion [10] and design effect of 2.

Multistage sampling technique was used to select household which has under-five children. From 29 rural kebeles 9 were randomly selected and household which has under-five children were selected using systematic random sampling technique after having the list of mother-child pair from the previous survey. A total of 590 mothers of index child aged under-five years were interviewed in February 2012.

\subsection{Measurements}

Data were collected using structured questionnaires. The questionnaires were pre-tested for its understandability by $5 \%$ of sample size in a kebele which was not included in the study. Nine 12 grade completed data collectors were recruited and trained on the sampling procedure, interview technique and data collection methods. Principal investigators and four trained supervisors monitored the overall quality of the data collection. In this study, Diarrhea was defined as a child with loose or watery stool for three or more times during a 24-hour's period in the household within two weeks period prior to the survey, as reported by the mother/caretaker of the child.

\subsection{Data Processing and Analysis}

The data were entered and analyzed using SPSS (SPSS Inc. version 16.0, Chicago, Illinois). Descriptive statistics (frequencies, proportion and chi- square test) were used to describe the study population in relation to relevant variables. $\mathrm{P} \leq 0.05$ was used, to consider association between variables was statistically significant.

\subsection{Ethical Considerations}

Ethical clearance was obtained from Ethical Review Board of Arba Minch University. Permission was obtained from Arba Minch District Health Office. Written informed consent was obtained from surrogate of the study participants after clear explanation about the purpose of the study. Oral rehydration solutions (ORS) was given for children who were found diarhea positive at the time of data collection, but children who were found severely ill were referred to the nearest health facility for better management.

\section{Results}

\subsection{Socio-Economic Characteristics of the Households}

A total of 590 households were included in this study and complete response was obtained from all (100\%) respondents. The mean age of mothers at the birth of index child was $29.5(\mathrm{SD} \pm 6.7)$. The majority of mothers 366 $(62 \%)$ were with no formal education and $517(87.6 \%)$ mothers were housewives by occupation. The mean household family size of the study population was 5.7 ( $\mathrm{SD} \pm 2.1$ ) persons (see table 1).

Table 1. Socio-economic characteristics of the households in Arba Minch District, Southern Ethiopia, 2012

\begin{tabular}{lcc}
\hline \multicolumn{1}{c}{ Variables } & Frequency & Percent (\%) \\
\hline Marital status & 565 & \\
Married & 25 & 95.7 \\
$\quad$ Single & 366 & 4.3 \\
Mothers education level & 224 & 62.0 \\
No formal education & & 38.0 \\
Primary and above & 517 & \\
occupation of mother & 40 & 87.6 \\
Housewife & 32 & 6.8 \\
Merchant & & 5.4 \\
Others] & 462 & \\
Ethnicity & 91 & 78.7 \\
Gamo & 34 & 5.8 \\
Wolayita & & \\
Others** & &
\end{tabular}




\begin{tabular}{lcc}
\hline \multicolumn{1}{c}{ Protestant } & 371 & 62.9 \\
\multicolumn{1}{c}{ Orthodox } & 205 & 34.6 \\
\multicolumn{1}{c}{ Muslim } & 14 & 2.4 \\
Mean age of mothers & \multicolumn{2}{c}{$29.5(\mathrm{SD} \pm 6.7)$} \\
$\begin{array}{l}\text { Mean household family } \\
\text { size }\end{array}$ & \multicolumn{3}{c}{$5.7(\mathrm{SD} \pm 2.1)$} \\
\hline
\end{tabular}

*= government employee; daily laborer ** = Amara, Gurage and Oromo

\subsection{Characteristics of Children Living Environment}

From the total of 590 households, 580 (98\%) had dwelling with mud floor. Majority of dwelling houses 390 $(66 \%)$ had no partition room. Fifty $(9 \%)$ of the households had no latrine. The mean per capita per day water consumption of the households was $6.5(\mathrm{SD} \pm 4)$ liters. More than one-third of households (33.7\%) used drinking water from unprotected sources. Only 191(32.4\%) mothers have a comprehensive knowledge about the cause of diarhea and its transmission methods. (See table 2).

Table 2. The characteristics of children living environment in Arba Minch District, Southern Ethiopia, 2012

\begin{tabular}{|c|c|c|}
\hline Variables & Frequency & Percent (\%) \\
\hline \multicolumn{3}{|l|}{ Floor of the house } \\
\hline Mud & 439 & 74.4 \\
\hline Cement & 151 & 25.6 \\
\hline \multicolumn{3}{|l|}{ Number of room } \\
\hline 1 & 390 & 66 \\
\hline 2 & 110 & 18.6 \\
\hline$\geq 3$ & 90 & 15.4 \\
\hline \multicolumn{3}{|l|}{ Availability of latrine } \\
\hline Yes & 540 & 91.6 \\
\hline No & 50 & 8.4 \\
\hline \multicolumn{3}{|l|}{ Type of latrine } \\
\hline Traditional pit latrine & 463 & 78.5 \\
\hline Ventilated improve latrine & 127 & 21.5 \\
\hline \multicolumn{3}{|l|}{ Waste disposal } \\
\hline Proper disposal & 475 & 80.5 \\
\hline Improper disposal & 115 & 19.5 \\
\hline \multicolumn{3}{|l|}{ Source of water } \\
\hline Protected source & 391 & 66.3 \\
\hline Unprotected source & 199 & 33.7 \\
\hline \multicolumn{3}{|l|}{ Distance from water source } \\
\hline$\leq 30$ minute & 503 & 85.4 \\
\hline$>30$ minute & 87 & 14.6 \\
\hline \multicolumn{3}{|l|}{ water transportation container } \\
\hline With lid & 496 & 84.1 \\
\hline Without lid & 94 & 15.9 \\
\hline \multicolumn{3}{|l|}{ home based water treatment } \\
\hline Yes & 99 & 16.8 \\
\hline No & 491 & 83.2 \\
\hline \multicolumn{3}{|l|}{$\begin{array}{l}\text { Comprehensive knowledge about } \\
\text { diarrhea }\end{array}$} \\
\hline Yes & 191 & 32.4 \\
\hline No & 399 & 67.6 \\
\hline $\begin{array}{l}\text { Mean per capita water } \\
\text { consumption }\end{array}$ & 6.5 & $(\mathrm{SD} \pm 4)$ \\
\hline
\end{tabular}

\subsection{Child Demographic and Mothers' Behavioral Characteristics}

Two hundred forty five children $(41.5 \%)$ were age 24 and above months; and 193 (32.7\%) were in age category of $0-5$ months respectively. Majority of the children were females $325(55.1 \%)$. In this study $180(30.5 \%)$ children have experienced diarrhea in the two weeks preceding the survey (see table 3).

Table 3. Description of child demographic and mothers'behavioral characteristics in Arba Minch District, Southern Ethiopia, 2012.

\begin{tabular}{|c|c|c|}
\hline Variables & Frequency $(n=590)$ & Percent (\%) \\
\hline \multicolumn{3}{|l|}{ Child sex } \\
\hline Male & 265 & 44.9 \\
\hline Female & 325 & 55.1 \\
\hline \multicolumn{3}{|l|}{ Child's age } \\
\hline $0-5$ months & 193 & 32.7 \\
\hline $6-23$ months & 152 & 25.8 \\
\hline 24 months \& above & 245 & 41.5 \\
\hline \multicolumn{3}{|l|}{ Birth order } \\
\hline First & 94 & 16.1 \\
\hline Second & 128 & 21.6 \\
\hline Third & 129 & 21.8 \\
\hline Fourth and above & 239 & 40.5 \\
\hline \multicolumn{3}{|l|}{ Currently Exclusive } \\
\hline \multicolumn{3}{|l|}{ Breastfeeding $(\mathrm{n}=200)$} \\
\hline Yes & 131 & 65.5 \\
\hline No & 69 & 34.5 \\
\hline $\begin{array}{l}\text { Measles vaccination } \\
(n=105)\end{array}$ & & \\
\hline Yes & 56 & 53.3 \\
\hline No & 49 & 46.7 \\
\hline \multicolumn{3}{|l|}{ Hand washing } \\
\hline Good & 508 & 86.1 \\
\hline Poor & 82 & 13.9 \\
\hline \multicolumn{3}{|l|}{ Diarrhea occurrence } \\
\hline Yes & 180 & 30.5 \\
\hline No & 410 & 69.5 \\
\hline
\end{tabular}

\subsection{The Occurrence of Diarhea and Its Home Management}

The prevalence of diarrhea among under-five index children $(n=590)$ in the study area was $30.5 \%$. Out of 180 mothers whose children had got diarrhea, 72 (40\%) gave oral rehydration solution and $53(29.4 \%)$ gave homemade fluid (salt and sugar solution), but 55 (31\%) didn't give anything to control or manage the diarrhea.

\subsection{Factors Associated With the Occurrence of Childhood Diarrhea}

Chi-square test of socio-economic, environmental, behavioral and child characteristics were done with respect to occurrence of diarrhea. Accordingly, mothers educational status $\left(\mathrm{X}^{2}=6.0397, \mathrm{df}=1, \mathrm{p}\right.$-value $\left.=0.0139\right)$; knowledge about diarrhea $\left(\mathrm{X}^{2}=5.0234, \mathrm{df}=1, \mathrm{p}\right.$-value=0.025), type of house floor $\left(\mathrm{X}^{2}=5.1426, \mathrm{df}=1, \mathrm{p}\right.$-value $\left.=0.023\right)$, number of rooms $\left(\mathrm{X}^{2}=30.46, \mathrm{df}=2, \mathrm{p}\right.$-value $\left.<0.00001\right)$, latrine type $\left(\left(X^{2}=25.5929, \mathrm{df}=1, \mathrm{p}\right.\right.$-value $\left.<0.00001\right)$, type of water transportation container $\left(\mathrm{X}^{2}=47.878, \mathrm{df}=1, \mathrm{p}\right.$-value $=$ $0.00001)$, and mother hand washing practice $\left(\mathrm{X}^{2}=\right.$ $15.4182, \mathrm{df}=1, \mathrm{p}$-value $=0.0001$ ) were found significantly associated with the occurrence of childhood diarrhea (see table 4). 
Table 4. Factors associated with the occurrence of diarrhea among under-five children in Arba-Minch District, Southern Ethiopia, 2012.

\begin{tabular}{|c|c|c|c|c|}
\hline \multirow{2}{*}{ Variables } & \multicolumn{2}{|c|}{ Diarrhea occurrence } & \multirow{2}{*}{ X2(chi-square value) } & \multirow{2}{*}{ p-value } \\
\hline & Yes $(\%)$ & No (\%) & & \\
\hline \multicolumn{5}{|l|}{ Mother educational status } \\
\hline No formal education & $125(34.2 \%)$ & $241(65.8 \%)$ & \multirow{2}{*}{6.0397} & \multirow{2}{*}{$0.0139 *$} \\
\hline With formal education & $55(24.6 \%)$ & $169(75.4 \%)$ & & \\
\hline \multicolumn{5}{|l|}{ Floor of the house } \\
\hline Mud & $145(33 \%)$ & $294(67 \%)$ & \multirow{2}{*}{5.1426} & \multirow{2}{*}{$0.0233 *$} \\
\hline Cement & $35(23.2 \%)$ & $116(76.8 \%)$ & & \\
\hline \multicolumn{5}{|l|}{ Number of rooms } \\
\hline One & $85(21.8 \%)$ & $305(78.2 \%)$ & \multirow{3}{*}{30.46} & \multirow{3}{*}{$<0.00001 *$} \\
\hline Two & $55(50.0 \%)$ & $55(50.0 \%)$ & & \\
\hline Three \& above & $40(44.4 \%)$ & $50(55.6 \%)$ & & \\
\hline \multicolumn{5}{|c|}{$\begin{array}{c}\text { Comprehensive knowledge about } \\
\text { diarrhea }\end{array}$} \\
\hline No & $110(27.6 \%)$ & $289(72.4 \%)$ & \multirow{2}{*}{5.0234} & \multirow{2}{*}{$0.0250^{*}$} \\
\hline Yes & $70(36.6 \%)$ & $121(63.4 \%)$ & & \\
\hline \multicolumn{5}{|l|}{ latrine available } \\
\hline No & $15(30 \%)$ & $35(70 \%)$ & \multirow{2}{*}{0.0067} & \multirow{2}{*}{0.9349} \\
\hline Yes & $165(30.5 \%)$ & $375(69.5 \%)$ & & \\
\hline \multicolumn{5}{|l|}{ Type of latrine } \\
\hline Traditional pit latrine & $118(25.5 \%)$ & $345(74.5 \%)$ & \multirow{2}{*}{25.5929} & \multirow{2}{*}{$<0.00001 *$} \\
\hline Ventilated improve latrine & $62(48.8 \%)$ & $65(51.2 \%)$ & & \\
\hline \multicolumn{5}{|l|}{ Waste disposal system } \\
\hline Improper disposal & $39(33.9 \%)$ & $76(66.1 \%)$ & \multirow{2}{*}{0.7810} & 03768 \\
\hline Proper disposal & $141(29.7)$ & $334(70.3)$ & & $0.3 / 68$ \\
\hline Source of water & & & & \\
\hline Unprotected source & $66(33.2 \%)$ & $133(66.8 \%)$ & & 02172 \\
\hline Protected source & $114(29.2)$ & $277(70.8 \%)$ & 1.0002 & $0.3 \Gamma 72$ \\
\hline water transportation container & & & & \\
\hline With lid & $123(24.8 \%)$ & $373(75.2 \%)$ & 17878 & م 0001 * \\
\hline Without lid & $57(60.4 \%)$ & $37(39.4 \%)$ & $4 / .8 / 8$ & $0.00001^{*}$ \\
\hline Home based water $\mathrm{Rx}$ & & & & \\
\hline Yes & $30(30.3 \%)$ & $69(69.7 \%)$ & 00024 & 0.0611 \\
\hline No & $150(30.6 \%)$ & $341(69.4 \%)$ & 0.0024 & 0.9011 \\
\hline Age of the child & & & & \\
\hline $0-5$ months & $45(23.3 \%)$ & $148(76.7 \%)$ & & \\
\hline $6-23$ months & $60(39.5 \%)$ & $92(60.5 \%)$ & 2.02001 & 0.1554 \\
\hline 24 months and above & $75(30.6 \%)$ & $170(69.4 \%)$ & & \\
\hline Child birth order & & & & \\
\hline First & $24(25.5 \%)$ & $70(74.5 \%$ & & \\
\hline Second & $40(31.3 \%)$ & $88(69.7 \%)$ & 3.0704 & 00779 \\
\hline Third & $29(22.4 \%)$ & $100(77.6 \%)$ & 3.10704 & $0.01 / 19$ \\
\hline Fourth & $87(36.4 \%)$ & $152(63.6 \%)$ & & \\
\hline Hand washing practice & & & & \\
\hline Poor & $44(47.8 \%)$ & $48(52.2 \%)$ & 154182 & $00001 *$ \\
\hline Good & $136(27.3 \%)$ & $362(72.7 \%)$ & 15.4182 & $0.0001^{*}$ \\
\hline
\end{tabular}

*Statistical Significance at $\mathrm{p} \leq 0.05$

\section{Discussion}

This study showed that the prevalence of childhood diarrhea among under-five index children was about $31 \%$ in the study area. This figure was relatively high when compared with findings from southern part of Ethiopia which was $25.5 \%$ [10]. This could be due to the difference in basic environmental conditions and behavioral characteristics of caretakers.

The Findings of this study also showed that mother education level, knowledge of diarhea, type of house floor, number of rooms, latrine type, type of water transportation container and mother hand washing practice were significantly associated with the occurrence of childhood diarhea. Studies conducted in Thailand, Nigeria and other countries also indicated that age of the child, economic status, quality and quantity of water, availability of sanitary facilities, and level of maternal education, household economic status, environmental hygiene and feeding practices are important factors for the occurrence of diarrheal diseases [11-14].

The study indicated that level of maternal education was 
associated with childhood diarrhea. This finding was consistent with a study done in Ghana. Findings from Ghana revealed that the prevalence of diarrhea varies according to education of mothers which was relatively high among children of mothers with no education [14].

The study also indicated that knowledge of diarhea in mothers was associated with the occurrence of diarhea. This indicates that Medias (radio, television), village health workers and medical facilities should work hard as they are the main source of information on diarhea to the public.

In this study the type of house floor, number of rooms, latrine type, and type of water transportation container were associated with diarhea. But, availability of latrine, waste disposal system and the source of water were not associated with diarhea which contrasts with previous study in Ghana where water availability, sanitary facilities and hygienic practices were associating factors for the occurrence of diarrheal disease [14].

This study also indicated that mother hand washing practice was associated with diarrheal morbidity. Similarly studies indicated that poor handling of food is the main causes of diarrhea occurrence and other infectious disease [12-14]. Since mothers are the main care givers for their children they should wash their hand in order to prevent diarrhea and occurrence of others hygiene related disease.

The findings of the study also showed that out of 180 mothers whose child had gotten diarrhea, about $31 \%$ of mothers didn't give anything to control or manage the diarhea. This is an area where decision makers and policy makers need to give focus. Early onset of complete nutrition in acute diarrhea especially in developing countries, where malnutrition and diarrhea are more common, has several potential benefits such as decreasing stool volume and decreasing the duration of diarrhea [4-7].

According to WHO, Center of Disease Control and USAID recommendations for management of diarrhea, commercially available solutions made of appropriate amounts of sodium, potassium and glucose or oral rehydration solutions are used for rehydration if patients can consume or drink the required volumes; otherwise appropriate intravenous fluids may be used [6-8]. Scholars also recommended two general methods for an effective treatment of diarrheal disease, ORS and zinc supplementations [7-9].

For the better management of diarhea the national guideline in Ethiopia also recommends, counseling mothers on the three rules of home treatment giving extra fluid, continue feeding and advice the mother when to return health facility [15-16].

\subsection{Limitations}

- $\quad$ Since there is no study conducted in Ethiopia, this study might be a base line of health planners and other researchers. Being the study community based also is the strength. However, due to the nature of cross sectional study it is difficult to establish cause effect relationship between the exposure and outcome variables.

\section{Conclusions}

The results of the study show that the prevalence of diarhea is $30.5 \%$, which was significantly associated with factors, namely mother education level, knowledge about diarrhea, type of house floor, number of rooms, latrine type, type of water transportation container and mother hand washing practice (after going to toilet and before feeding children). The findings of the study also showed that out of 180 mothers whose child had got diarrhea about $31 \%$ of mothers could not give anything to manage the diarhea.

Overall, the findings have important policy implications for health intervention and support the view that women education level of at least primary should be achieved to reduce childhood diarrheal morbidity. Reducing diarrhea morbidity involves providing better sanitation for the entire population and hygiene of the person caring of the child. Despite prevention is better than cure, sometimes prevention activities might fall and lead to morbidity. Therefore, counseling mothers on the three rules of home treatment; give extra fluid, continue feeding and advise the mother when to return health facility is very crucial for the control and the prevention of the disease. Further study, to identify factors affecting home management of childhood diarhea, was recommended.

\section{Competing Interests}

The authors declare that they have no competing interests.

\section{Authors' contributions}

SM participated in design of the study, drafted the manuscript, coordinated the field work and analyzed the data. DT participated in the design of the study; drafting of the manuscript and review of article.

\section{Acknowledgement}

We acknowledge the study participants for their information provided and the institutions for their cooperation. The study was funded by Arba Minch University, Ethiopia.

\section{References}

[1] Gerald T. Keusch, O F, Alok B. Disease Control Priorities in Developing Countries 2001, 371-388

[2] World Health Organization. Integrated management of childhood illness 2010.

[3] Federal Ministry of Health. National strategy for infant and 
young child feeding, Addis Ababa, Ethiopia 2004.

[4] Food and Nutrition Technical Assistance Project (FANTA). Summary Indicators for Infant and Child Feeding Practices 2002 .

[5] Bernadette D, Jose M, Randa S. Special Issue Base World Health Organization Expert Consultation on Complementary Feeding; Food and Nutrition Bulletin 2003; 24(1): 3-141.

[6] World Health Organization. Report of the global consultation on Summary of guiding principles for complementary feeding of the breastfed child, Geneva Switzerland 2001.

[7] Center for disease control. Guidelines for the Management of Acute Diarrhea. Department of Health and Human Services in United states 2008.

[8] USAID. Guidelines for New Diarrhea Treatment Protocols for Community-Based Healthcare Workers 2005.

[9] Graciete O, Vieira L, Silva R. Tatiana D, Vieira O. Child feeding and diarrhea morbidity. Journal de Pediatric 2003; 79(5):449-54.

[10] Central Statistical Authority [Ethiopia] and ORC Macro: Ethiopia Demographic and Health Survey 2011. Addis
Ababa. Maryland: Ethiopia and Calverton; 2011.

[11] Khaled Y. Morbidity and risk factor of diarrheal diseases among under five children in rural Upper Egypt. Journal of Tropical pediatrics 2000,46:282-287.

[12] Yilgwan CS, Yilgwan G, Abok II. Domestic Water Sourcing and the Risk of Diarrhea: A Cross-Sectional Survey of a semi-urban Community in Nigeria. Journal of Medicine $2005,5(1): 34-37$

[13] Calistus W, Alessio P. Factors associated with diarrhea among children less than 5 years old in Thailand: a secondary analysis of Thailand multiple indicator cluster survey. J Health Res 2009, 23: 17-22

[14] Kwasi Owusu B MK. Childhood diarrheal morbidity in the Accra Metropolitan Area, Ghana: socio-economic, environmental and behavioral risk determinants. Journal of Health and Population in Developing countries 2005.

[15] Drug Administration and Control Authority of Ethiopia Contents. Standard treatment guideline for primary hospitals, Jan 2010.

[16] Guerrant. Practice Guidelines for the Management of Infectious Diarrhea. Clinical Infectious Diseases 2003; $2: 331-50$ 